\title{
An Analysis of Indicators of E-Citizen with an Emphasis on the Realization and Expansion of E-Cities (Case Study: Tabriz Metropolis, Iran)
}

\author{
Rasoul Babanasab (Corresponding author) \\ Ph.D Student of Geography and Urban Planning, University of Isfahan, Isfahan, Iran \\ E-mail: Rasoulbabanasab@yahoo.com \\ Dr. Asghar Zarabi \\ Full Professor of Geography and Urban Planning, University of Isfahan, Isfahan, Iran \\ E-mail: a.zarabi@geo.ui.ac.ir
}

Dr. Masoud Taghvaei

Full Professor of Geography and Urban Planning, University of Isfahan, Isfahan, Iran

E-mail: m.taghvaei@geo.ui.ac.ir

Received: March 1, 2015 Accepted: March 25, 2015

doi:10.5296/emsd.v4i1.7173 URL: http://dx.doi.org/10.5296/emsd.v4i1.7173

\begin{abstract}
The present study has been conducted with the aim of investigating indicators of e-citizen with an emphasis on the realization and expansion of e-cities in Tabriz Metropolis. The study is an applied-developmental one using a descriptive-analytical method, and a survey research for collecting appropriate data. In fact, to collect data, field and documentary methods were employed. The data were collected from 354 questionnaires distributed among the citizens residing in the ten areas of Tabriz. Then, using SPSS software, and ranking variables using Likert scale, the data were analyzed.

The findings of the research indicate that the quality of citizens' access to ICT facilities and electronic service providers is relatively appropriate. There is a direct significant correlation
\end{abstract}


of the indicators of e-citizen with the reception of different representations of ICT and realization and expansion of the e-city. This coefficient value in the scope of the study is 0.433. in addition, citizens' attitudes towards the expansion of using ICT and the realization of e-city is that the application of ICT and e-city, in case of its realization, will be effective on different social, economic, environmental and physical dimensions and in general the access to urban suitable development. In general, above $79 \%$ of the citizens agreed with the necessity of the expansion of

ICT and the realization of e-city; in other words, their tendency to use ICT is high. Therefore, the urban society of Tabriz accepts the effect of modern technologies as a great possibility and opportunity for accessing urban sustainable development.

Keywords: ICT, E-citizen, e-city, Urban sustainable development, Tabriz Metropolis

\section{Introduction}

Nowadays, there is a close and inseparable association among technology, wealth, and power. The most obvious technological upheavals of this age is information and commination products. This upheaval is called the ICT Revolution. Therefore, ICT is a comprehensive phenomenon effective on the complete range of human activities from personal applications to economic and political ones because it is considered as a multipurpose, flexible instrument, having multiple capabilities, which provides the possibility of appropriate solutions in the form of personal and local applications for realizing different needs (Motlagh and Behrouznia, 2009: 8).

The new age, with reliance on new information and communication technologies, has provided different solutions for a lot of problems, and has been able to aid the urban society and provide solutions for the available problems (Hatami Nasab et al. 2011: 2). Cities should be lively and dynamic; therefore, it should be noticed that they have a sustainable root. In other words, some theorists have noticed that cities can speak to their residents and be in relation with their citizens verbally (Navabakhsh and Motlaq, 2009:891). Building an e-city and taking steps in the stage of IT is an undeniable opportunity and one of the basic pre-requisites for attaining urban sustainable development. An e-city is constructed from three dimensions of technology, people and society and refers to cities which have ICT infrastructures, and before a city can become smart, it should have information technology and knowledge of applying these facilities (Lovehagen and Bondesson, 2013: 175). E-city is a reality present according to the needs of people and society. If such conditions are neglected, their costs must be paid (Zeynali Azim et al, 2012:6615). E-cities can be considered as cities based on innovation and creativity, and a lot of metropolises in the world, by applying ICT and cities based on virtual spaces, have been able to find appropriate statuses in the domain of sustainable development.

In Iran, urbanization trend has increasing grown especially in such metropolitans as Tehran, Mashhad, Isfahan, Tabriz and etc. According to 2011 people and housing census in Iran, urbanization rate has reached to $71.4 \%$. Regarding the sharp rise in population and lack of 
infrastructure, living in metropolises, in addition to its particular difficulties for citizens, has faced urban managers with serious challenged in managing cities and providing services for citizens. Among these challenges, one can refer to the lack of relevance of the capacity of cities with their population, heavy congestion of cars in streets, increase in fuel consumption, time waste of citizens in heavy car congestions, change in local biology, air pollution, environment pollution, spread of diseases as result of different pollutions, lack of transparency, less participation of citizens in urban decisions and etc. the Metropolis of Tabriz is no exception.

Concerning new technologies resulting in the complexity of social life, facilitation of different affairs of life and utilizing the advantages of IT in doing everyday affairs without requiring for visiting service organizations personally is an undeniable necessity, and solving the challenges of traffic, air pollution, environment, saving time and costs are realized by constructing e-cities. This aim will be realized in the Metropolis of Tabriz when the term "e-city" moves towards operationalization and then, urban life may be more convenient with its all problems. Therefore, the quiddity of applying this technology and its effects on urban environments should be identified, and principled planning should be adopted in this line in order that managers and citizens exert their efforts for optimal usage of this technology in solving urban problems and challenges.

The important point in implementing the e-city project is an issue called "e-citizen"; in other words, it is better that as long as citizens will not have attained a favorable level of electronic services in terms of cultural, educational and information aspects, and the traditional and paper and pencil system of service providing is continued and the project will not attained. The realization of e-city requires the attention to two certain issues; providing infrastructures and culture promotion as well as training e-citizens. Therefore, regarding the mentioned cases, each research conducted on this technology in different fields, particularly issues related to metropolises, can enjoy great importance.

\subsection{Research Objectives}

Among the most important objectives of the present study is to closely investigate the quality of citizens' access to ICT facilities and centers of electronic service providing, indicators of e-citizen, the reception of different ICT representations, and electronic city, in case of its realization, and its effects on different dimensions of urban sustainable development from citizens' perspective.

\subsection{Research Hypotheses}

The present study has been conducted in line with investigating the following research hypotheses:

- It seems that in the City of Tabriz, citizens' access to ICT facilities and electronic service providing centers for doing electronic activities is high.

-There is a significant correlation of the indicators of e-citizen with the reception of different representation of ICT and e-city. 


\section{Macrothink}

- From citizens' perspectives, the application of ICT and e-city, in case of its realization, is effective on urban sustainable development.

\section{Literature Review and Theoretical Framework}

In the $21^{\text {st }}$ century, called the Information Age, citizens with information literacy are cornerstones of their societies in which social justice is prevalent, they enjoy potential economic growth, and individuals require information skills for doing their own personal, professional and even recreational activities. Pearson (2006), in an article, investigated the role of ICT in building creative, healthy, attractive cities and places better for working, living and entertaining, and stated that the most important effects of IT on health is the governance and security of societies,

and if the application and adoption of this technology be conducted appropriately, the future urban societies will be happy, progressive, healthy and participatory, and cities feel loneliness less. Sinnari and Al-Nuaim (2012), in a research titled as "using mobile technology for electronic

participation of citizens", investigated the application of mobile technology in providing data and information for citizens in real times for reinforcing their electronic participation and that of local authorities in their decision making, or sending emergency alerts to local authorities and receiving important alerts from local authorities. In addition, this research developed an interactive electronic system. "Help Citizens" connects local and urban authorities to citizens using cell phones to ensure their security based on reporting high traffic ways and risk alerts which may threaten the life of each citizen or infrastructures. In an introduction titled "an investigation of ICT role in decreasing inner city trips (case study of Isfahan, Iran), Soltani et al. (2008) put emphasis on the reinforcement of such vital infrastructures as cultural infrastructures in heightening the success of ICT use in Isfahan. In a paper titled "ICT influence on Arak urban development", Motlagh and Behrouznia(2009) recommend such proposals as citizenship training as urban development basics, education of virtual literacy to citizens as the most important goals of network societies, consideration of such points as certification of electronic citizenship as essential proficiencies for citizens, education of electronic citizenship skills to children and youth, reinforcement of citizens' attitude toward ICT, creation of social networks and so on in order to use ICT optimally and improve its effects on urban environments. In a paper titled "an analysis of ICT condition and its role in urban management and planning, case study of Najafabad, Isfahan”, Taghvaei et al. (2010) believe that Iranian cities have potential capacity for using ICT and accepting technologies, but need comprehensive plans for proper use of that capacity and the enjoyment of the benefits of ICT depends on the proper coordination of all sectors in urban environments. Babanasab et al (2014), in a research tiled as "an analysis of the state of factors affecting the realization of e-city in metropolises (case study: Tabriz Metropolis) concluded that the literacy of using ICT, Integrated Management, investment in networks and infrastructure, ICT skilled manpower, the culture of using ICT, the access to centers of electronic service providing in urban areas and the initial communication and infrastructural instrument ca be effective on the electricity of Tabriz. 


\section{Ml Macrothink}

Environmental Management and Sustainable Development

ISSN 2164-7682 2015, Vol. 4, No. 1

E-city provides the possibility of electronic access of citizens to all offices, inner-city spots and needed different information 24 hours in weekly basis in a stable, reliable, safe and confidential manner (Jalali, 2005: 47). E-city is able to solve such problems as traffic congestion, administrative corruption, social inequalities and so on in real cities (Zeynali Azim et al, 2012: 6615). In addition, it helps research for sustainable models for urban development and decrease in the problems and disorders of unsustainable cities (Kotval, 1999: 40).

Couclelis defines E-city as "coordinated and network-based relationships for doing usual tasks of citizens via electronic method, which those tasks had been done personally in common real cities" (Couclelis, 2001). Odendaal believes that E-city is a city in which opportunities created by ICT have been invested on in order to multiply the success and effectiveness of such investments (Odendaal, 2003:586). It is the best ground for ICT development all over the world. Daily, many people face many problems doing their daily chores in small and large cities. IT bears a significant responsibility in facilitating and accelerating those affairs (Soltani, 2009: 26).

The most basic and fundamental activities for creating E-city should be focused on the construction and development of communications infrastructures. An E-city should enjoy communications infrastructures and a proper legal environment so that E-business may be possible in that environment and E-commerce may be implemented. It is essential to establish suitable safety for citizens and regulations proper for E-cities. E-signature, electronic literacy of citizens and so on are among other infrastructures of E-cities for citizens or so-called networkers

are considered as vital pillars of E-cities and they should live in such cities. Meanwhile, proper physical texture should be prepared. Also, the other needed infrastructures are active management and true networking culture (Khansari, 2007: 35).

The individual familiar with IT and can use electronic services of an e-city, is called an e-citizen. In other words, the citizens of information societies using the benefits of IT, are called e-citizens (Fathian and Mahdavinour, 2005: 237).

In an e-city, it is the e-citizen who should live in this city and to use electronic services, he should have information literacy. Manuel Castles believes that information city requires information citizens and only by this presumption one should enter the online world (Veisi and Gheisivandi, 2011: 42).

\section{Research Methodology}

The present research is an applied-developmental research design and its method of data collection is documentary, analytical and survey research. The population include all citizens living in the ten areas of Tabriz which based on the census of 2011, they were 1494998 individuals. In the present study, and using Cochrane's formula (Hafeznia, 2007: 140), the sample size was determined to include 322 participants and for more confidence, 10 percent was added to the samples and the sample size included 354. This number was distributed proportionate to the population size of each area among the ten regions of the City of Tabriz. 
The instrument for collecting data was a researcher-made questionnaire and the sampling method was simple random sampling. To conduct descriptive and analytical statistics, SPSS was used and to answer the research hypothesis, Pearson correlation coefficient, and One-sample t-test were sued. To measure the validity of the questionnaire, several copies of the primary questionnaire were submitted to some theorist and their ideas were adopted in the questionnaire. In addition, to investigate the reliability of items related to the research, Cronbach's alpha coefficient was used. The value of Cronbach's alpha coefficient was 0.902 which indicated the reliability of description and relations between variables scientifically. In the present study, the indices of access to ICT facilities at home and centers of electronic service providing in cities, indices of electronic citizen and the reception of ICT effects and electronic city, in case of its realization, were evaluated from the perspectives of citizens. All items are designed based on Likert scale.

Table 1. Indicators and items of the research

\begin{tabular}{|c|c|}
\hline Indicators & Items \\
\hline $\begin{array}{l}\text { Access to ICT facilities } \\
\text { and centers of electronic } \\
\text { service providing }\end{array}$ & $\begin{array}{l}\text { 1. ATM access, } 2 \text {. Internet cafes, } 3 \text {. Police }+10,4 \text {. counter government offices, } 5 . \\
\text { Computer services offices, } 6 \text {. Computer and internet access at home, } 7 \text {. Enjoying } \\
\text { computers proportionate to households' needs }\end{array}$ \\
\hline e-citizen & $\begin{array}{l}\text { 1. The use of mobile phones during the day and night. } 2 \text {. The degree of working with } \\
\text { computers. 3. Familiarity with computers. } 4 \text {. Using the Internet. 5. Using emails and } \\
\text { chatting. 6. Doing banking activities in electronically. } 7 \text {. E-purchase. } 8 \text {. Doing travel } \\
\text { activities electronically. 9. Realizing scientific, research and educational needs the } \\
\text { Internet, 10. Doing electronic decision making activities. 11. Spending leisure time via } \\
\text { the internet and computers. 12. Using entertaining virtual spaces. 13. Electronic health } \\
\text { activities. 14. Attaining news of the city via the Internet. 15. Studying and reviewing } \\
\text { news events online. 16. The degree of using counter government offices, post banks, } \\
\text { internet cafes, etc. 17. Watching general training and promoting digital skills. } 18 \text {. } \\
\text { Visiting the portal of the Municipality and Governorate of Tabriz. }\end{array}$ \\
\hline $\begin{array}{l}\text { reception of different } \\
\text { representations of ICT } \\
\text { and e-city and its } \\
\text { realization }\end{array}$ & $\begin{array}{l}\text { Social effects: } \\
\text { 1. Easier access to public attitudes and increase in the cultural level. } 2 \text {. Increase in } \\
\text { security level and order in urban environments. } 3 \text {. Improvement in access to urban } \\
\text { services. } 4 \text {. Increase in participation in urban affairs. } 5 \text {. Increase in communication of } \\
\text { urban neighborhood. } 6 \text {. Increase in higher vitality and enhancement in urban order. } 7 . \\
\text { The change in the process of decision making in organizations. } \\
\text { Economic effects: } \\
\text { 1. Increase in capabilities of urban managers. } 2 \text {. Decrease in administrative corruption } \\
\text { with clarification of processes and preventing bribe and nepotism. 3. Creating new, } \\
\text { diverse and cheap employment. } 4 \text {. Decrease in access and communication costs. } 5 \text {. } \\
\text { Saving in time, space and place. } \\
\text { Environmental effects: } \\
\text { 1. Decrease in urban traffic. } 2 \text {. Decrease in air and noise pollution. } 3 \text {. Promotion of } \\
\text { environmental health in cities and maintaining the environment. } \\
\text { Physical effects: } \\
\text { 1. Increase in cultural virtual spaces. } 2 \text {. Increase in green spaces and sport spaces by } \\
\text { deleting redundant users. } 3 \text {. De-centralization of urban centers and high traffic areas. } 4 . \\
\text { Teleworking. } 5 \text {. Diversification of urban spaces. }\end{array}$ \\
\hline
\end{tabular}




\section{Research Findings and Discussion}

In the current research, studied area is the metropolitan Tabriz. It is the capital of East Azerbaijan Province in Iran. This city is the largest one in Northwestern Iran and Azerbaijani-residing regions and is recognized as administrative, communicational, commercial, political, industrial and military pole of the region. Its area is 24451 hectares and its population was 1378935 in 2006 and reached to 1494998 in 2011(www.tabriz.ir). According to East Azerbaijan Telecommunications Company, till the end of 2013, network externality coefficient of land phone, mobile phone and internet had ascendant trend. Furthermore, network externality coefficient of land phone was $46.43 \%$, mobile phone $123.8 \%$ and internet $35.85 \%$. In terms of E-service centers and offices, the data regarding governments' front counters and rural ICT offices has been provided: Till the end of 2013, 111 governments' front counters and 27 rural ICT offices were delivering E-services in different parts of Tabriz. Also, till the end of 2013, there were 633 public payphones in different districts if Tabriz (East Azerbaijan Telecommunication Company, 2013). According to 2011 Iranian people and housings census, among total 453886 households living in Tabriz, 196625 households had personal computers.

In order to develop Tabriz facing several urban challenges, urban managers and planners attempts at reducing urban problems for citizens through the establishment of E-city and the deliverance of E-services. Of course, Tabriz has been a pioneer in most of the fields and the investigation of Tabriz Telecommunication Company, Municipality and Municipality's Statistics and IT Department shows if coordinated and organized operational plans are observed with proper road maps, the first Iranian E-city would be established in Tabriz. Of the effective steps taken in this regard include setting up a datacenter as the Municipality's commands room, developing exclusive optical fiber for the Municipality, running several information portals and websites, carrying out three stages of E-citizen project aiming at enhancing citizens' E-literacy level, opening E-citizen club, issuing identification E-cards for citizens, planning for setting up 500 websites within Tabriz Municipality Complex, designing the most equipped and largest city portal in Iran, installing the Municipality's exclusive radio mast, carrying out networking master plan in Tabriz Municipality Complex, running up systems for delivering electronic services in housing development affairs and issuing building permit in all districts of the Municipality, designing Tabriz search software, establishing a system for recommendations, designing inner-city transportation supervision smart system, setting up tolls E-payment system, drawing new tourism map for Tabriz, designing the Municipality's master system of auctions and bids and opening the Municipality's call center.

Regarding the fact tht the first step in realizing e-city is to familiarize citizens with ITC and applying it in the everyday life as well as the receiving the representations of its effectiveness. To investigate and identifying the status quo of the City of Tabriz in terms of citizens' access to ICT facilities and electronic centers of service providing, indicators of e-citizen, understanding beliefs and receiving citizens towards the effectiveness of ICT and realizing e-city, the copies of the designed questionnaire were distributed in the ten areas of Tabriz and their results were analyzed by SPSS. The descriptive and analytical results are as follows: $61.59 \%$ of the participants were men and $38.41 \%$ were women. $20.05 \%$ of them were below 
20 years old, $33.9 \%$ were aged $21-30$ years old, $28.53 \%$ were $31-40$ years old, $14.13 \%$ were $50-41$ years old, and $3.39 \%$ were aged above 50 years old. In addition, $8.86 \%$ of the participants held a degree below diploma, $28.81 \%$ held diploma, $16.38 \%$ held associate diploma, $35.31 \%$ BA, and $10.74 \%$ held MA and higher degrees.

\subsection{Testing Research Hypotheses}

4.1.1 It seems that in the City of Tabriz, citizens' access to ICT facilities and electronic service providing centers for doing electronic activities is high.

To investigate citizens' access to ICT facilities and electronic service providing centers, one-sample t-test was used. Using this test, the hypothesis is investigated as follows:

$\mathrm{H}_{0}$ : the mean scores of the indicator is equal or less than 3 .

$\mathrm{H}_{1}$ : the mean scores is higher than 3 .

As observed in table 2, P-values of access to ATM, internet cafes, , and computer and internet access at home are less than 0.05 and p-values of access to police +10 , counter government offices and enjoying computers proportionate to households' needs are higher 0.05 . Regarding that the mean scores of indicators of access to ATM, internet cafes, and computer and internet access at home are higher than 3, and the upper and lower limit of the confidence interval are positive; therefore, it is inferred that the access to these indicators is high and in other indices, the mean scores of the sample is equal 3 and the upper and lower limit of the confidence interval are negative. This shows that the access to police +10 , counter government offices and Enjoying computers proportionate to households' needs are at moderate levels.

Regarding the fact that the mean scores of all indicators are higher than 3, and the upper and lower limit of the confidence interval are positive; therefore, it can be stated that the access to ICT facilities and electronic service providing centers in the City of Tabriz is in a favorable state.

Table 2. investigating citizens' access to ICT facilities and electronic service providing centers

\begin{tabular}{|c|c|c|c|c|c|c|c|c|}
\hline \multicolumn{9}{|c|}{ One-Sample Test } \\
\hline \multicolumn{9}{|c|}{ Test Value $=3$} \\
\hline & Mean & $\begin{array}{c}\text { Std. } \\
\text { Deviation }\end{array}$ & $\mathrm{t}$ & $\mathrm{df}$ & $\begin{array}{c}\text { Sig. } \\
\text { (2-tailed) }\end{array}$ & $\begin{array}{c}\text { Mean } \\
\text { Difference }\end{array}$ & \multicolumn{2}{|c|}{$\begin{array}{c}95 \% \text { Confidence } \\
\text { Interval of the } \\
\text { Difference }\end{array}$} \\
\hline & & & & & & & Lower & Upper \\
\hline ATM & 3.6864 & 1.15902 & 11.143 & 353 & .000 & .68644 & .5653 & .8076 \\
\hline Internet cafes & 3.1780 & 1.10085 & 3.042 & 353 & .003 & .17797 & .0629 & .2930 \\
\hline Police +10 & 2.8757 & 1.23744 & -1.890 & 353 & .060 & -.12429 & -.2536 & .0051 \\
\hline $\begin{array}{c}\text { counter government } \\
\text { offices }\end{array}$ & 3.0621 & 1.107026 & 1.056 & 353 & .292 & .06215 & -.0536 & .1779 \\
\hline Computer services & 3.2203 & 1.07616 & 3.852 & 353 & .000 & .22034 & .1078 & .3328 \\
\hline
\end{tabular}




\begin{tabular}{|c|c|c|c|c|c|c|c|c|}
\hline offices & & & & & & & & \\
\hline $\begin{array}{c}\text { Computer and } \\
\text { internet at home }\end{array}$ & 3.2825 & 1.17064 & 4.540 & 353 & .000 & .28249 & .1601 & .4049 \\
\hline $\begin{array}{c}\text { enjoying computers } \\
\text { proportionate to } \\
\text { households' needs }\end{array}$ & 3.0452 & 1.10019 & .773 & 353 & .440 & .04520 & -.0698 & .1602 \\
\hline All access indicators & 3.1929 & .70735 & 5.131 & 353 & .000 & .19290 & .1190 & .2668 \\
\hline
\end{tabular}

4.1.2 There is a significant correlation of the indicators of e-citizen with the reception of different representation of ICT and e-city.

The independent variable is the indicators of e-citizen and the dependent variable is the reception of different representation of ICT, and the expansion and relation of e-city. To test the above hypothesis, Pearson correlation coefficient was used for determining the degree of correlation between the variables using the interval scale. Statistical hypothesis are as follows:

$\mathrm{H}_{0}: \mathrm{r}=0$

$\mathrm{H}_{1}: \mathrm{r} \neq 0$

Regarding the fact that the calculated significance level (sig=0.000) is less that the predicted one $(\boldsymbol{\alpha}=0.05)$; therefore, the null hypothesis is rejected and the research hypothesis is confirmed. In other words, the higher the degree of citizens' electronic preparedness, the more it is effective on the perception of realizing the representations and expansion of e-city. In addition, the magnitude of the correlation coefficient as 0.433 indicates the positive and high correlation between the two variables.

Table 3. investigating the correlation between indicators of e-citizen and the reception of different representation of ICT and e-city.

\begin{tabular}{|l|l|r|r|}
\hline \multicolumn{5}{|c|}{ Correlations } & e-citizen & $\begin{array}{l}\text { the reception of different representation of ICT } \\
\text { and e-city }\end{array}$ \\
\hline \multirow{2}{*}{ e-citizen } & & 1 & $.433^{* * *}$ \\
& $\begin{array}{l}\text { Pearson } \\
\text { Correlation }\end{array}$ & & .000 \\
\cline { 2 - 5 } & Sig. (2-tailed) & & 354 \\
\cline { 2 - 5 } & $\mathrm{N}$ & $.433^{* *}$ & 1 \\
\hline \multirow{2}{*}{$\begin{array}{l}\text { the reception of different representation of ICT } \\
\text { and e-city }\end{array}$} & $\begin{array}{l}\text { Pearson } \\
\text { Correlation }\end{array}$ & .000 & 354 \\
\cline { 2 - 5 } & Sig. (2-tailed) & 354 & \\
\cline { 2 - 4 } & $\mathrm{N}$ & & \\
\hline$* *$ Correlation is significant at the 0.01 level (2-tailed). &
\end{tabular}




\section{Macrothink}

Environmental Management and Sustainable Development

ISSN 2164-7682

2015, Vol. 4, No. 1

4.1.3 From citizens' perspectives, the application of ICT and e-city, in case of its realization, is effective on urban sustainable development.

To investigate citizens' attitudes towards the effect of the application of ICT and e-city, in case of its realization on urban sustainable development, one sample t-test was used. Using this test, the hypothesis was investigated as follows:

$\mathrm{H}_{0}$ : the mean scores of the indicator is equal or less than 3 .

$\mathrm{H}_{1}$ : the mean scores is higher than 3 .

As observed in table 4, P-values of social, economic, environmental, and physical dimensions and in general, all dimensions of urban sustainable development are less than 0.05 . Therefore, it is inferred that the mean scores of the sample is not equal 3 and the equality of the mean scores with 3 is not confirmed. Regarding that the mean score of each of the dimensions and in general, all dimensions are high than 3, and the upper and lower limit of the confidence interval are positive; therefore, it can be said that from the perspective of citizens, the application of ICT and e-city, in case of its realization, are effective on urban sustainable development of the City of Tabriz.

Table 4. investigating the effects of ICT and e-city, in case of its realization, on the dimensions of urban sustainable development from citizens' perspectives

\begin{tabular}{|l|c|c|c|c|c|c|c|c|}
\hline \multicolumn{9}{|c|}{ One-Sample Test } \\
\hline \multicolumn{2}{|c|}{} & Mean & $\begin{array}{c}\text { Std. } \\
\text { Deviation }\end{array}$ & T & Df & $\begin{array}{c}\text { Sig. } \\
\text { 2-tailed })\end{array}$ & $\begin{array}{c}\text { Mean } \\
\text { Difference }\end{array}$ & $\begin{array}{c}\text { 95\% Confidence } \\
\text { Interval of the } \\
\text { Difference }\end{array}$ \\
\hline $\begin{array}{l}\text { Social dimension } \\
\text { Economic }\end{array}$ & 3.6796 & .75681 & 16.895 & 353 & .000 & .67958 & .6005 & .7587 \\
\hline dimension & 3.8153 & .82365 & 18.623 & 353 & .000 & .81525 & .7292 & .9014 \\
\hline $\begin{array}{l}\text { Environmental } \\
\text { dimension }\end{array}$ & 3.7938 & .85519 & 17.464 & 353 & .000 & .79379 & .7044 & .8832 \\
\hline $\begin{array}{l}\text { Physical } \\
\text { dimensions }\end{array}$ & 3.5847 & .79226 & 13.887 & 353 & .000 & .58475 & .5019 & .6676 \\
\hline $\begin{array}{l}\text { Urban } \\
\text { sustainable } \\
\text { development }\end{array}$ & 3.7183 & .71021 & 19.030 & 353 & .000 & .71834 & .6441 & .7926 \\
\hline
\end{tabular}

\section{Research Results and Suggestions}

One of the most important fields of changing and consequently, developing individuals' social life in the contemporary world is the change and transformation in information and communication fields. This issue is rooted in the urgent need of $21^{\text {st }}$ human beings to knowledge by which they can make themselves compatible to the complex conditions and rapid flow of transformations. In this arena, cities and particularly metropolises as dense 
population centers and one of the most attractive places for individuals' residents, are severely influenced by it. The realization of e-city, in addition to creating a modern model in cities, provides individuals' and managers' access to the needs of an urban developed, creative, pure, cultural, knowledge-based and development-centered society.

E-city is an issue which for the first time, was proposed in Iran in 2000. In 2001, World Congresses of Electronic and Internet Cities were held with more than 1500 experts, authorities and people in Kish Island, and its unknown dimensions in Iran were introduced. The first movement for implementing e-city in Iran started with presenting the project of e-city in Kish and continued with presenting projects such as "major ICT plans of the Iran's municipalities of metropolises" including seven metropolises of Isfahan, Ahwaz, Tabriz, Karaj, Qom, and Mashhad. Now, measures for getting Iran's metropolises electronic is to be conducted.

The present study investigated the indicators of e-citizen with the focus on realization and expansion of e-cities from the perspectives of 354 citizens. The following results were obtained from the present study:

In terms of indicators of e-citizen, the degree of citizens' use of telephone, computers and their familiarity with computers, the Internet, doing banking activities electronically, eliminating scientific needs via the Internet and spending leisure time with computers and the Internet is relatively acceptable and higher than the moderate level. In some activities such as e-purchase, e-treatment, travels, and etc. the lowness of the mean scores is due to poor infrastructures. the quality of citizens' access to ICT facilities and electronic service providers is relatively appropriate. There is a direct significant correlation of the indicators of e-citizen with the reception of different representations of ICT and realization and expansion of the e-city. This coefficient value in the scope of the study is 0.433 . in addition, citizens' attitudes towards the expansion of using ICT and the realization of e-city is that the application of ICT and e-city, in case of its realization, will be effective on different social, economic, environmental and physical dimensions and in general the access to urban suitable development. In general, above $79 \%$ of the citizens agreed with the necessity of the expansion of ICT and the realization of e-city;

As a result, the realization of e-city causes creating a ground in which citizens with creativity and innovation, provide more opportunities for helping their city and urban managers for promoting economic, social and cultural affairs of their own city. It means that using optimally ICT and establishing e-city result in urban sustainable development. Since Tabriz is the center of Eastern Azerbaijan Province and is considered as the biggest city of the west-north region of Iran, as well as it is an industrial city, has been faced with diverse challenged such as traffic, pollution, and etc. along with these challenges, the role of ICT and e-city, in case of its realization, can have very invaluable application for citizens to have a better experience of their lives. Participants of the present study, as the citizens of the City of Tabriz, believes that applying ICT and the electronic facilities in the city are considered as motivations of development and their tendencies towards this issue are higher. 


\section{Macrothink}

Environmental Management and Sustainable Development

ISSN 2164-7682

2015, Vol. 4, No. 1

In line with optimally using ICT, providing infrastructures, culture promoting and training e-citizens, the following suggestions are presented:

- Exploiting the experience of successful states in the establishment of E-cities;

- Serious attention of the public and private sectors to investing on communication networks and infrastructures;

- Increase in expert human forces of ICT in offices and centers of electronic service providing in the city;

- Producing training programs for promoting the benefits of electronic cities among citizens and urban authorities;

- Establishing electronic or IT literacy movement for training those illiterate of technologies for learning and being motivated for applying technologies in their everyday lives and preventing the waste of opportunities and costs;

- Revision of the quality of training e-citizens by Information Technology Department of Tabriz Municipality;

- Paying attention to unified urban management and the improvement of inter-organizational affiliations in order to benefit more from the merits of electronic cities;

- Serious attention of urban managers to promoting culture among citizens and staff working in organizations to use ICT optimally;

- Training virtual literacy to citizens and allocating financial facilities in order to promote electronic citizenship;

- Increasing net cafes, e-service centers, ICT offices, e-banks, catalogs, banners and billboards, and urban advertisement televisions in order to promote performing civic affairs electronically;

- Running social networks such as chat rooms among urban districts in order to enhance participation and unity of citizens and give recommendations and complaints about urban projects, the performance of the authorities and so on;

- Training public and private employees to update themselves regarding informing online visitors and users truly;

- Developing fast and economic wide-band network.

\section{References}

Babanasab, R., Zarabi, A., \& Taghvaei, M. (2014), An Analysis of the Indexes Effective on the Establishment of Electronic City in Metropolitans (Case Study: Metropolitan Tabriz, Iran), International Journal of Regional Development, 1(1), 65-78. http://dx.doi.org/10.5296/ijrd.v1i1.6533 


\section{Macrothink}

Environmental Management and Sustainable Development

ISSN 2164-7682

2015, Vol. 4, No. 1

Couclelis, H. (2001). The Social Construction of Digital City. USA: University of California press.

East Azerbaijan Telecommunication Company, (2013).

Fathian, M., \& Mahdavi Nour, S. H. (2004). Foundations of IT Management, Iran University of Science and Technology Publications, Iran.

Hafeznia, M. R. (2007) An Introduction the Research Method in Humanities, Samt Publications, Tehran, Iran.

Hataminasab, S. H., Taleifar, R., Asgharinejad, M., \& Dehghani, A. (2011). An Evaluation of Managers' Viewpoints on Electronic Cities (Case Study: Yazd Electronic City, Iran). Business Management Researches Quarterly, 3(5), 1-26.

Iran Statistics Center. (2011). Results of 2011 Iranian Housing and People Census. Tehran, Iran.

Jalali, A. A. (2005). Electronic City. Iran University of Science and Technology Publications, Iran.

Khansari, K. (2007). Current Citizen, Future Networker. ICT Use Development Monthly, 5(2), $34-40$.

Kotval, Z. (1999). Telecommunications, A realistic strategy for the revitalization of American Cities, Cities, 16(1), 33-41. http://dx.doi.org/10.1016/S0264-2751(98)00052-3

Lovehagen, N., \& Bondesson, A. (2013). Evaluating sustainability of using ICT solutions in smart cities - methodology requirements. Proceedings of the First International Conference on Information and Communication Technologies for Sustainability, ETH Zurich.

Motlagh, M., \& Behrouznia, P. (2009). An Investigation of ICT Influences on the Development of Cities (Case Study: Arak, Iran). Social Sciences Research Journal, 3(2), 7-38.

Navabakhsh, M., \& Motlagh, M. (2009). Effects of Urban Information and Communication Technology on Sustainable Development. Journal of Food, Agriculture \& Environment, 7(3\&4), 891-897.

Odendaal, N. (2003). Information and Communication Technology and Local overnance: Understanding the Difference between Cities in Developed and Emerging Economies. Computers, Environment and Urban Systems, 27, 585-607. http://dx.doi.org/10.1016/S0198-9715(03)00016-4

Pearson, I. (2006). The role of future ICT in city development. Foresight, 8(3), 3-16. http://dx.doi.org/10.1108/14636680610668036

Sinnari, D., \& Al-Nuaim, H., (2012), The Use of Mobile Technology for Citizen E-Participation, Networked Digital Technologies Communications in Computer and Information Science Volume 294, 2012, $p p$ 487-500. 


\section{Macrothink \\ Environmental Management and Sustainable Development \\ ISSN 2164-7682 2015, Vol. 4, No. 1}

http://dx.doi.org/10.1007/978-3-642-30567-2_41

Soltani, L., Zarabi, A., \& Zangiabadi, A. (2008). An Investigation of ICT Role in Reducing Requests of Inner-City Trips (Case Study: Isfahan, Iran). Isfahan University's Humanities Research Journal, 32(4), 1-18.

Soltani, M. (2009). Spatial Analysis of ICT Role in the Development of Electronic Tourism in Isfahan, Iran. MA Thesis of Geography Department, Isfahan University, Iran.

Taghvaei, M., Babanasab, R., \& Mousavi, S. C. (2010), An Analysis of ICT Condition and Its Role in Urban management and Planning (Case Study: Nadjafabad, Iran), Tabriz University's Geography and Planning Journal, 15(31), 25-49.

Veisi, A., \& Gheisivandi, A. (2011). Smart Cities, Book of the Month Art, No. 155, 36-45.

Zeynali Azim, A., Behnud, E., Zeynali, M., \& kasiri, S. (2012). Electronic city: A City of Today and Tomorrow. Journal of Basic and Applied Scientific Research, J. Basic. Appl. Sci. Res., 2(7), 6615-6621.

\section{Copyright Disclaimer}

Copyright for this article is retained by the author(s), with first publication rights granted to the journal.

This is an open-access article distributed under the terms and conditions of the Creative Commons Attribution license (http://creativecommons.org/licenses/by/3.0/). 